\title{
3D VIRTUALIZATION BY CLOSE RANGE PHOTOGRAMMETRY INDOOR GOTHIC CHURCH APSES. THE CASE STUDY OF CHURCH OF SAN FRANCISCO IN BETANZOS (LA CORUÑA, SPAIN)
}

\author{
A. Pérez $\operatorname{Ramos}^{\mathrm{a}} *$, G. Robleda Prieto ${ }^{\mathrm{a}}$ \\ ${ }^{a}$ Dept. of Technology and Graphical Representation, University School of Technical Architecture - University of La Coruña , Rúa \\ da Fraga 27, Campus da Zapateira 15008, La Coruña, Spain - araceli.perez.ramos@udc.es
}

\author{
Commission V, WG V/4
}

KEY WORDS: Cultural Heritage, Close Range, Photogrammetry, Low cost photogrammetric techniques, Point cloud, Virtualization.

\begin{abstract}
:
Virtualization using low cost photogrammetric techniques, is often replaced by Terrestial Laser Scanning inside churches. Especially in the case of Gothic churches where light penetrates the interior of the building difficulting shooting in proper condition to perform their restitution. The need to use Terrestial Laser Scaning for indoor virtualization is a significant increase in the final surveying cost. In these cases, the Terrestial Laser Scanning is used to generate dense point clouds that can produce high resolution models. However, many Terrestial Laser Scanners are not able to provide color images or can not reach the quality of images which can be obtained through a semiprofessional camera. So, digital photogrammetry is often used to make these models high resolution textures that Terrestial Laser Scanner based methodology is not capable of providing. This article aims to solved the problem posed by virtualizating Gothic churches indoors. Making that task more affordable exclusively by low cost photogrammetric techniques. The proposed methodology allows obtaining photographs in such a good conditions for virtualizing the target by point cloud. In order to verify the usefulness of the method, It has been decided to apply it to Gothic apse of the church of San Francisco in Betanzos (La Coruña). The equipment used is inexpensive and easy to carry: DSLR camera with 18-135 mm lens, tripod, lights and total station.
\end{abstract}

\section{INTRODUCTION}

Nowadays, heritage virtualizing is used as basis for multiple applications: documentation, monitoring, tours and virtual museums, augmented reality (AR) ...All them have in common the need of pre-generate a 3D model. Demanded requirements of these models will vary depending on the application, particularly model resolution (Visitini, 2009).

Data acquisition techniques commonly used are laser scanning and photogrammetry. These techniques are often mixed within a project in order to obtain results required or appropriate to the subsequent application of 3D model.

Inside buildings, similar to the case presented, the process commonly used involves using Terrestial Laser Scanners to generate volumes and geometries. However, laser scanner can not provide color images or image quality is not enough if we pursue a high resolution model. So, semi-professional cameras are used to obtain high quality images and build model texture. Methodology that combines laser scanning and photogrammetry provides good results (Visintini, 2009). Nevertheless, laser scanning dependence make it a high cost tecnique not available to many professionals. Furthermore, using both techniques entails doing work twice (Tucci, 2003).

Using photogrammetry as unique technique to survey allows for volumen and texture within a single workflow. (Pérez, 2011) Not to mention costs, as any profesional could afford equipment used.
The main problem in trying to virtualize a Gothic building indoors, or similar features, exclusively by photogrammetric techniques lies in difficulty to find proper lighting conditions, which should be as uniform as possible to get adequate restitution images, especially around windows and gaps opened in building walls (Ginovart, 2014).

This article aims to solved the problem posed by virtualizating Gothic churches indoors. Making that task more affordable exclusively by low cost photogrammetric techniques. The proposed methodology allows obtaining photographs in such a good conditions for virtualizing the target by point cloud. In order to verify the usefulness of the method, It has been decided to apply it to the apse. Since the apse is one of the most complex interior part of these kind of buildings.

\section{CHURCH OF SAN FRANCISCO}

The church of San Francisco, located in Betanzos, is in the english way to Santiago de Compostela. The convent patron was Fernán Pérez de Andrade "O Boo", who chose it as nobility pantheon. The only original part that remains of the church is the apse, the rest has undergone many changes througout history. It was part of a former convent that was attached to north wall and had been built in the late fourteen century. Gothic building with many Romanesque details like buttresses or capitals. Materials used are common in the area: granite quarries close to Betanzos, chestnut wood and tile. 


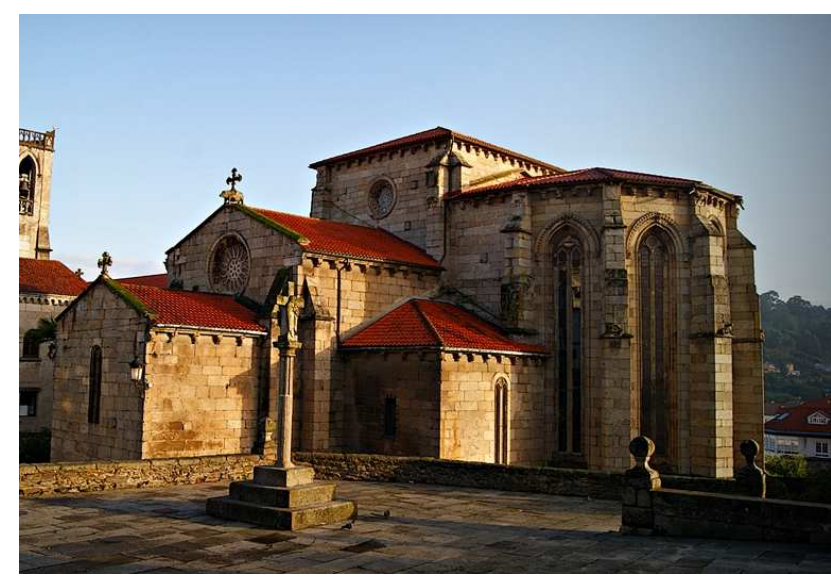

Figure 1. South view of San Francisco church.

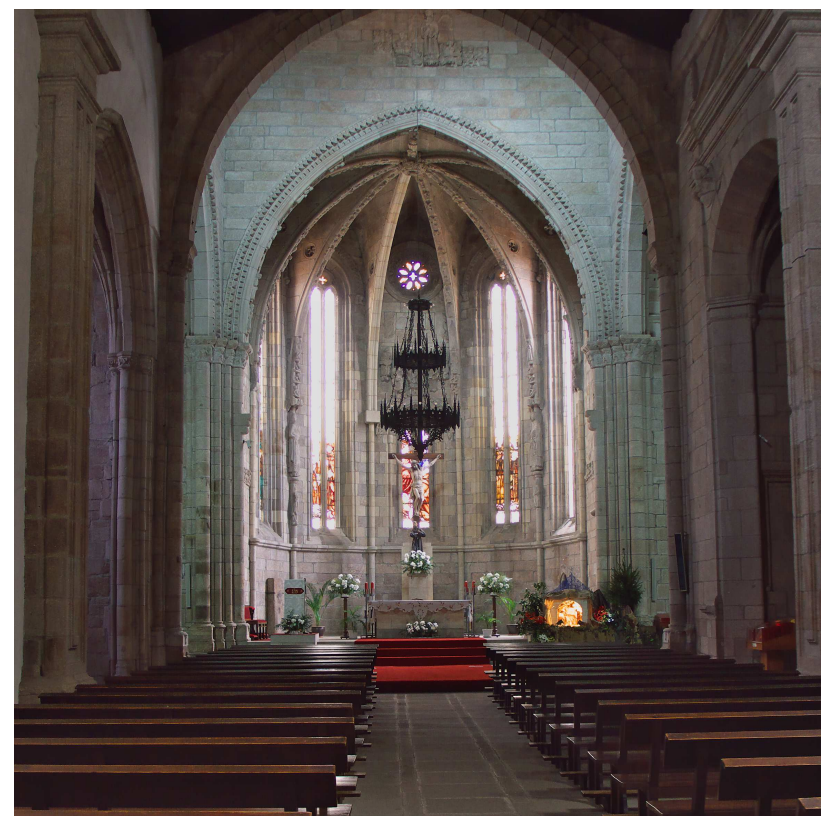

Figure 2. Interior view of San Francisco church.

\section{METHODOLOGY}

Restitution of any item requires good fieldwork planning in order to get a good result optimizing resources. Reducing time spent by caring fieldwork photography strategy and thus, time dedicated to fieldwork by reducing number of images and therefore time image processing by software.

To create a photorealistic indoor 3D model apse, geometry and texture generated must be accurate to reflect ornamental richness in detail.

Materials used are total station Leica TCR370, laser distancemeter Leica DISTO D410, Cannon EOS 550D SLR with $18-135 \mathrm{~mm}$ lens, tripod and lighting equipment.

\subsection{Pre-planning.}

Fieldwork was carried out according to pre-planning. Careful planning ensures success of shooting strategy, reducing processing time and avoid having to repeat visits for data collection. Photographed strategy is planned taken into account geometries and obstacles.

Calibrating camera in advance worths. In this case it has begun with camera calibration using template and it has been improved with later calibrations on 3D models. Camera parameters calculation have been adjusted gradually (on-thefield camera calibration). Best accuracies are achieved by calibrating the camera using a 3D object. Each focal length employed in the field must be calibrated.

\subsection{Fieldwork or data collection.}

3.2.1 Work enviroment recognition: First, place or select those points that serve as reference to establish our coordinate system and precision control points. Defects or damage from stones as checkpoints and coordinate system. It requires Topographical measurements.

Then, several measures are taken with laser distancemeter to ensure shooting strategy previously established conforms to reality.

3.2.2 Lighting conditions: Second, proper lighting settings are choosen availing lighting equipment. Trying to find uniformity and reduce shadows where posible.

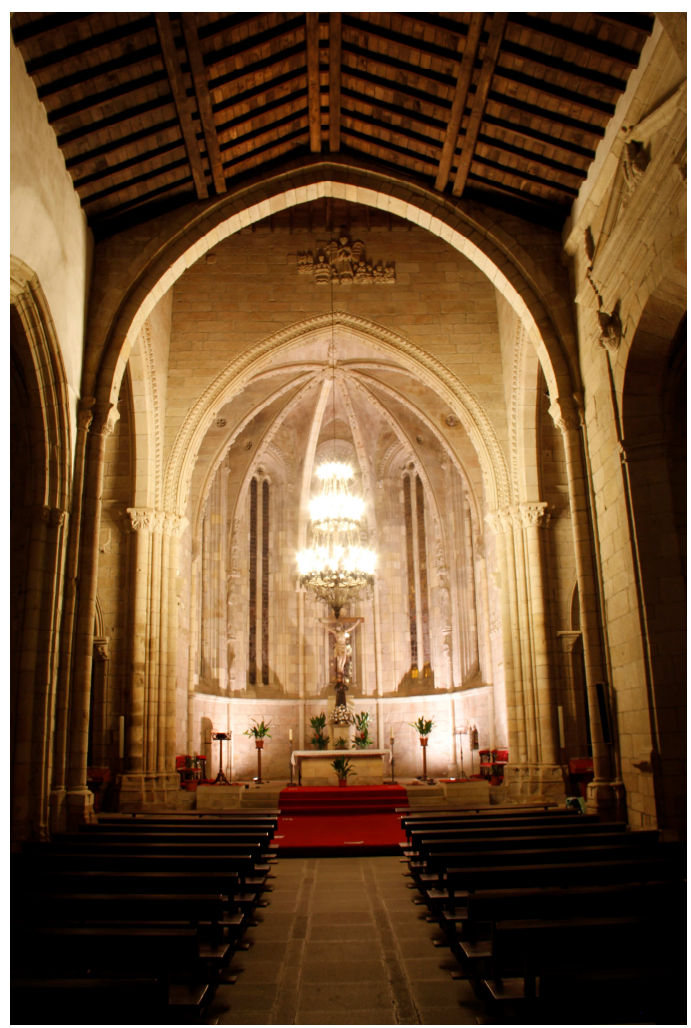

Figure 3. Lighting conditions settings (general). 


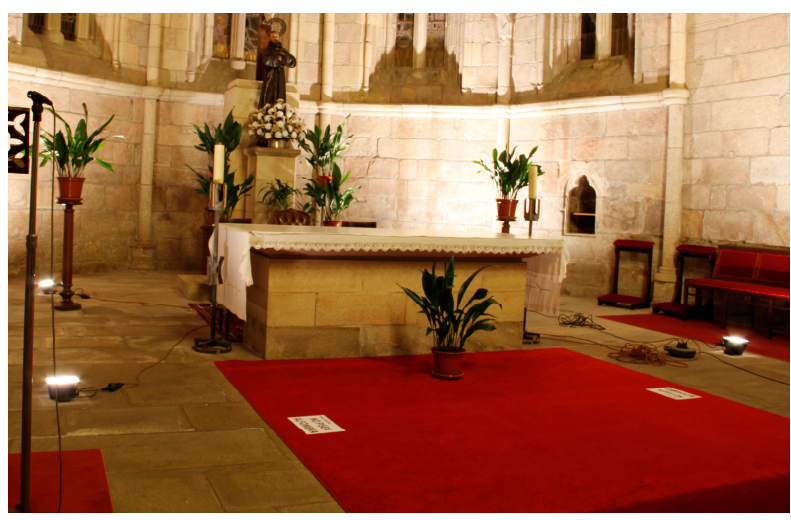

Figure 4. Lighting conditions settings (detail).

3.2.3 Photo Capture: When adequate lighting conditions are set, we can begin to take photograhs according to previously established strategy. Canon 550D SRL (18 megapíxels) with $18-135 \mathrm{~mm}$ lens is used. Converging shots are much more effective than divergent, so in transition zone wall-dome we ensure covering entire surface with converging shots. Shooting in RAW format with 5184 x 3456 pixels resolution. RAW format allows us to correct the photograph parameters photograph without losing quality

Photos were taken in $18 \mathrm{~mm}$ focal lengh, ISO-100, f/11 aperture value and $1 / 5 \mathrm{~s}$ shutter speed. Under these conditions using tripod is necessary to prevent camera shake and noise and to ensure pictures sharpness.

The images acquired for 3D virtualization should overlap, at least, around $60 \%$ in order to ensure automatic matching between homologous points.

Photo captured is a crucial point in photogrammetric technique process since it depends largely on the accuracy and finish of the model. Establish the most appropriate shooting conditions for each case requires practice.

3.2.4 Topographical measurements: Uniformly distributed points are measured with total station Leica TCR370 to set coordinate system and control model accuracy.

Unlike methodology that combines laser sacnning and photogrametry, photogrammetry do not need a lot of points to fit images and 3D geometry (Tucci, 2003). Few points (10 in this study case) are enough to set the coordinate system (3 points out of 10) and control model accuracy.

\subsection{Office Methodology or information processing.}

3.3.1 Selecting and Developing of images: Before starting restitution tasks, those images that will be used are selected avoiding blurs and trepidations. Once selected, photos in RAW format are developed. In such cases, where lighting conditions vary between different areas of item to virtualize, reducing differences in development process is tried (color and exposure), paying attention to details. A suitable development contributes to improve image matching whether automatic or manual.
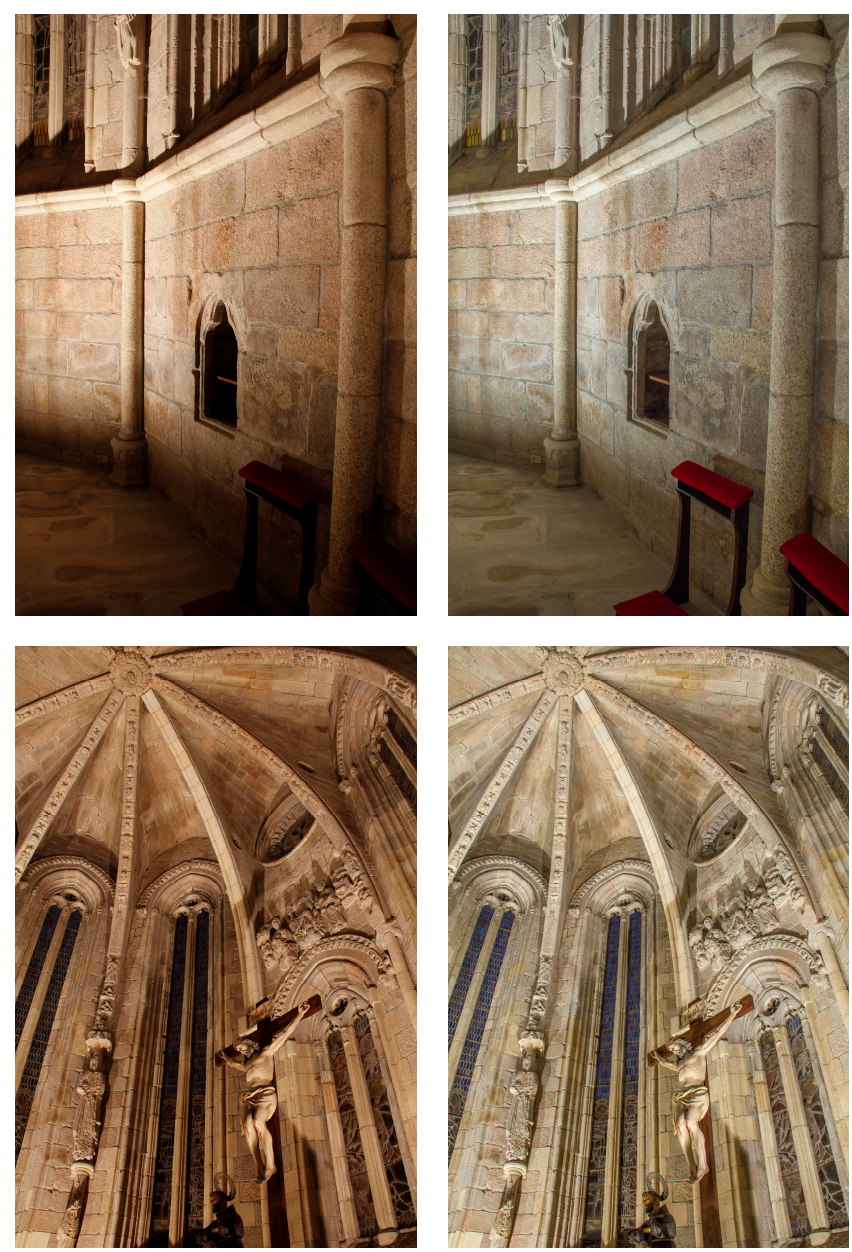

Figure 5. RAW development example.

Before(left) and after(right).

3.3.2 Restitution software: Data processing includes dense point clouds generating (3.641.273 points), scaling, rotating and translationing of model, building surfaces (635.932 faces) and texturing.

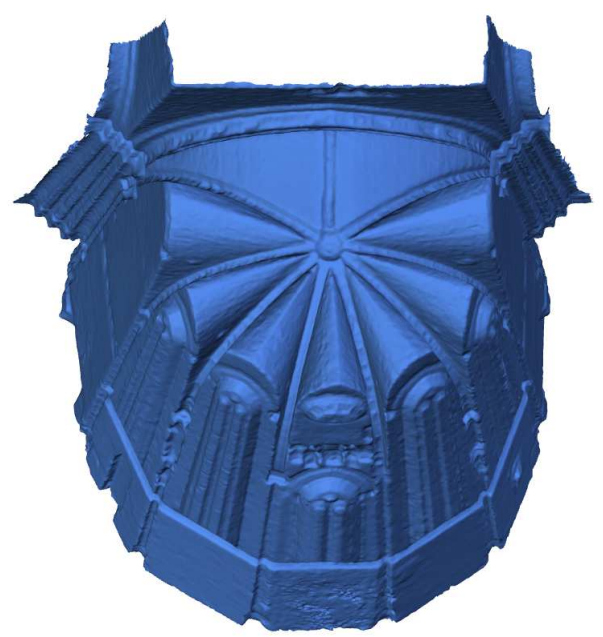

Figure 6. Mesh view with no texture (635.932 faces). 


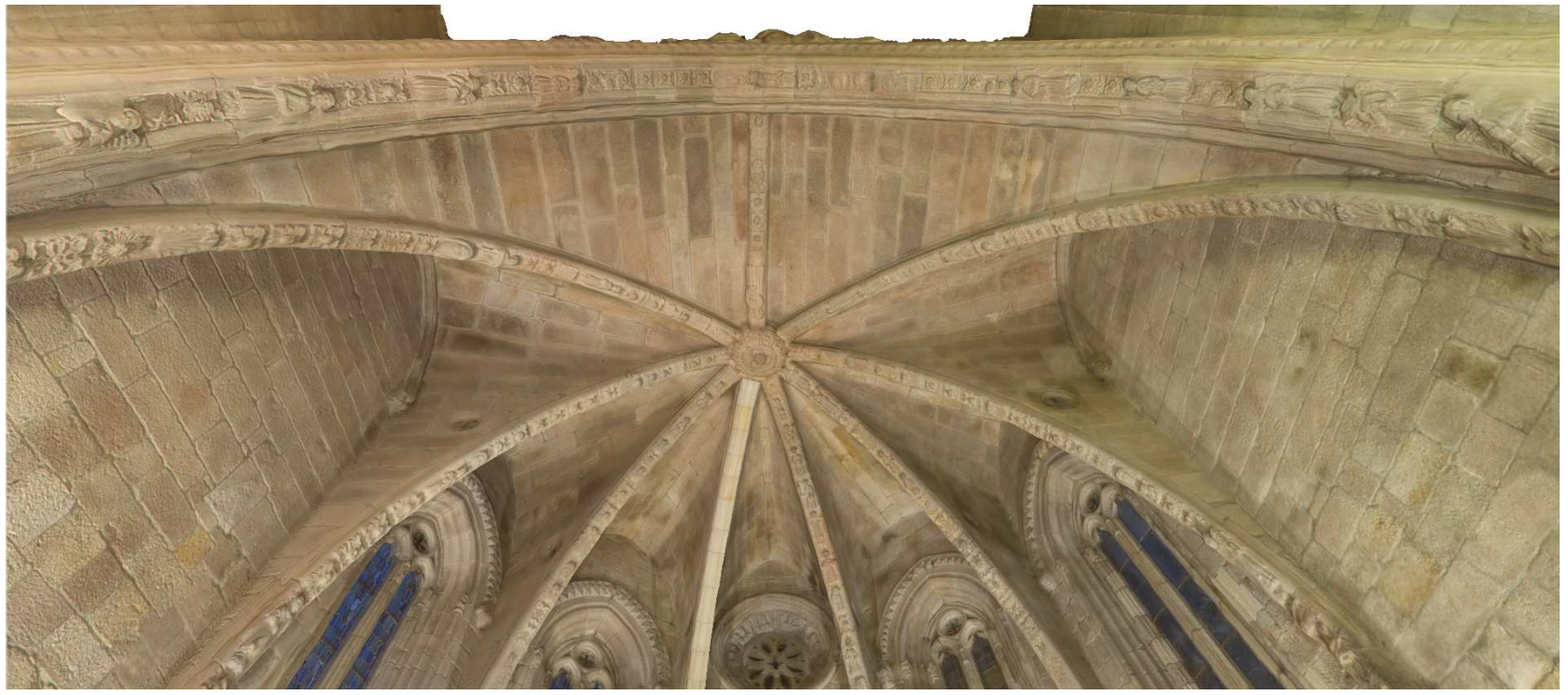

Figure 7. High resolution model. Level of detail view.

\section{RESULTS}

Agisoft PhotoScan Professional 1.0.4.1847 has been used to processing point cloud, mesh generation and textures application. The workflow within PhotoScan is easy, even for professionals who are not used to working with photogrammetry software.

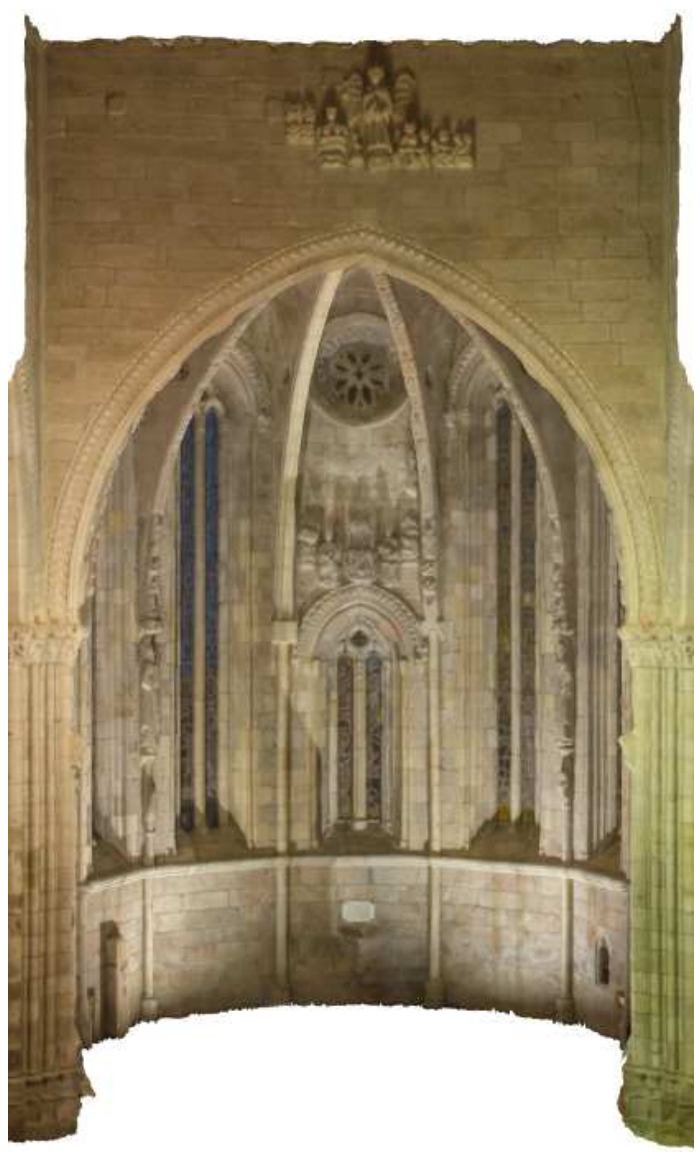

Figure 8. Front apse view.
Colored dense point cloud and Digital Surface Model are obtained following described methodology. These two products allow viewing on multiple 3D media. In addition, It provides alternative products: elevations, plans and sections as orthoimagery or vector drawing.

40 photograhs were enough to virtualize the apse. However, increasing the number of photograhs allowed us to eliminate those elements that do not belong to building as imagery, flowers, wires, lamps, speakers, furniture...

Obtained model was successful since it represents in detail ornamental elements of the apse and its texture. In this way, it constitutes a valuable document that registrates current apse conditions useful for future interventions or studies.

The best resolution that can be obtained in virtualized model is equivalent to pictures resolution. In this case the model has a minimun resolution around 8 pixels $/ \mathrm{cm}$. It increases in areas where photos were taken from a shorter distance.

\section{DISCUSSION}

The interior of Gothic buildings has features that makes virtualizing a complex and laborious task. Light entering through windows and other wall holes involves not optimal conditions for photo to restitution. In apses cases, space shape is an added difficulty. Thus, using lighting equipment and careful development become key points in this sort of work.

We have tried to find indoor light conditions as homogeneous as possible. However, it has been impossible to avoid some shadows as It can be seen in textured model.

One of the main drawbacks of this study case was impossibility to remove furniture and other items. This forced us to increase the number of photographs and therefore working time in data preparation and processing. 
The International Archives of the Photogrammetry, Remote Sensing and Spatial Information Sciences, Volume XL-5/W4, 2015 3D Virtual Reconstruction and Visualization of Complex Architectures, 25-27 February 2015, Avila, Spain

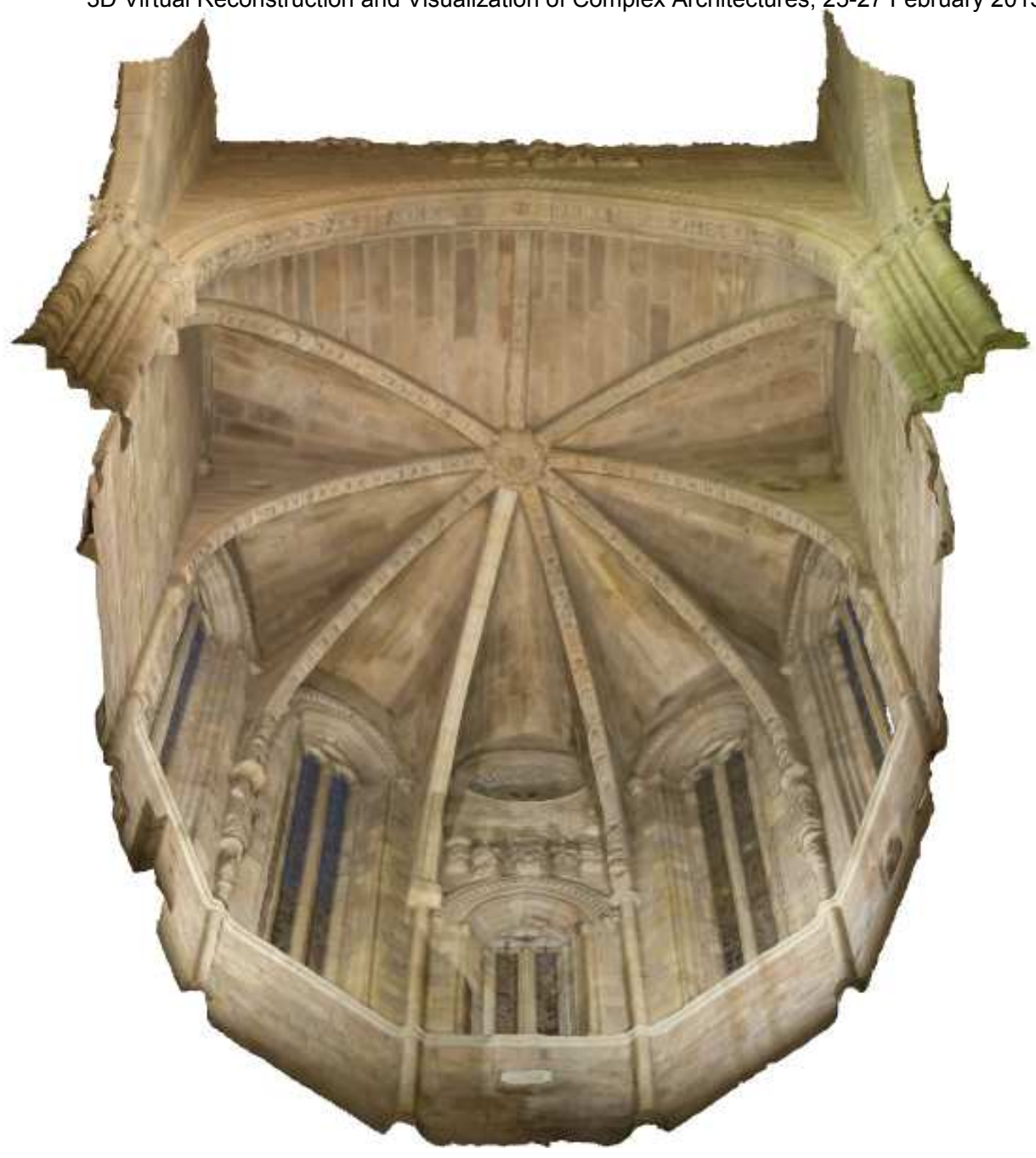

Figure 9. Apse vault general view. (Above)

Figure 10. High resolution nerve detail. (Right)

During meshing process, small gaps are automatically closed by software so it does not fit to reality in some areas. Thus, capitals top are not shown in photos leaving a point cloud hole closes automatically by software. This drawback is shared with laser scanning technique so, areas not reached by laser beam are also hollow in point cloud.

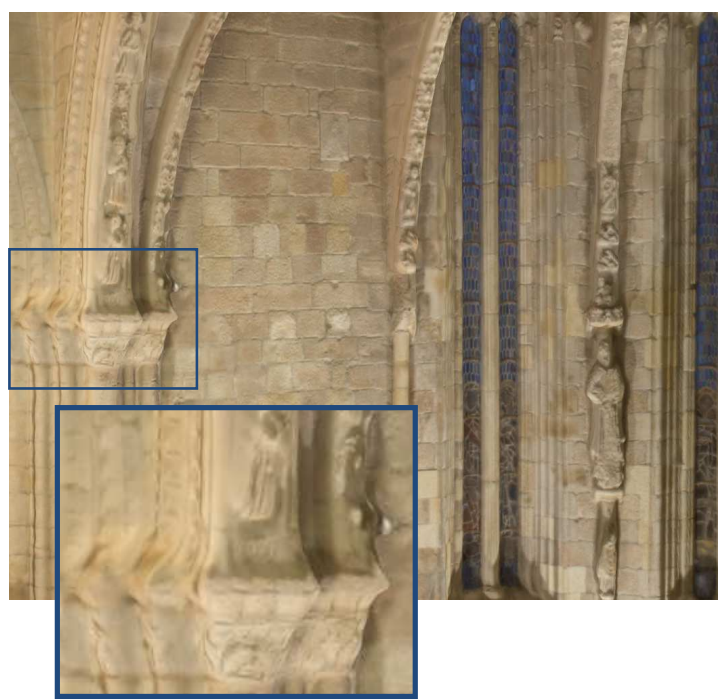

Figure 11. Areas do not fit to reality.
Something similar happens in texture generating, each triangle gets it from photo with the most perpendicular visual. Those areas are not visible in images taken so they have lower quality texture than others.

Using photogrammetry techniques can generate 3D geometry model and its texture within same workflow and within one software. Images adjust automatically to 3D model without making more tasks. Laser scanning would need extra tasks if high resolution model is pursued.

Data capturing by laser scanner is faster indoors, as few stations are required to generate a point cloud inside buildings with these characteristics (Sofocleous, 2006). Although point cloud is generated in real time, it requires cleaning. Furthermore, laser scanning usually requires images taken with an external camera and stablishing common points between images and 3D geometry for generating high resolution models.

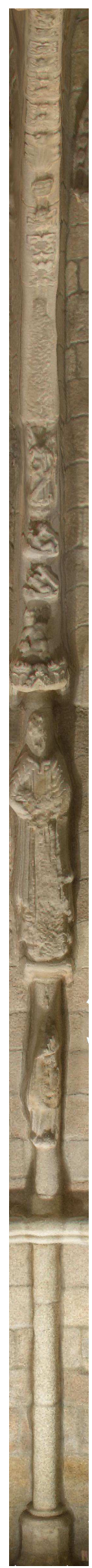




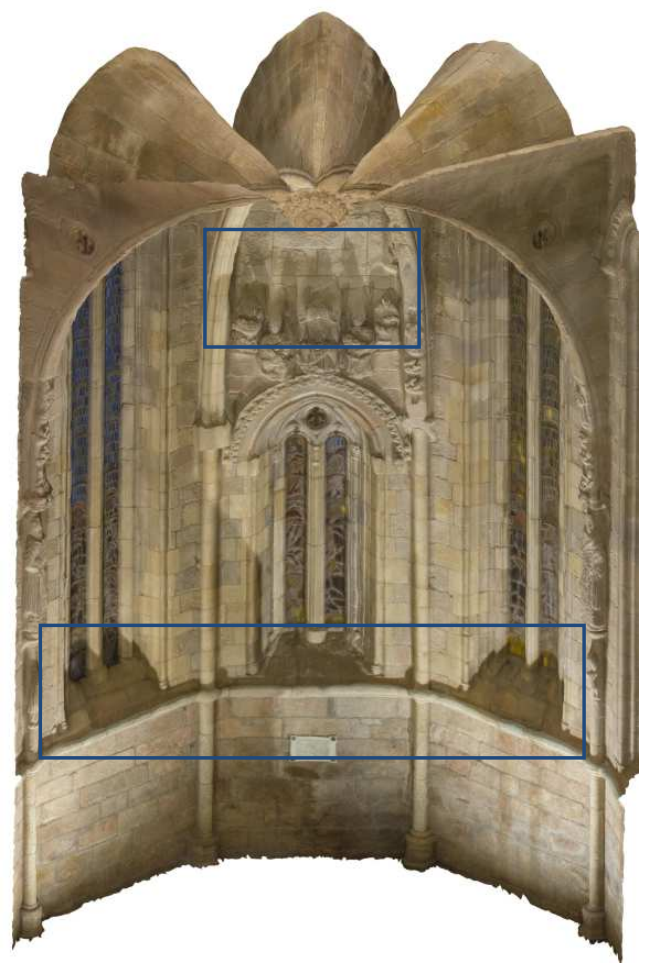

Figure 12. Shadows that could not be avoided.

Photogrammetry requires more stations to cover the whole area to virtualize and more time for taking images and generating point clouds by software although, time required for cleaning is lower. Additional images for generating high resolution models are no needed.

In laser scanner working, point cloud density is defined at data captured time and it can be reduced later while, in photogrammetric techniques point cloud density is defined during office work according to needs. Files generated by laser scanning are huge and heavy so, they usually need to be reduce in order to handle it easily.

\section{CONCLUSIONS}

The documentation inside Gothic buildings is a complex task. Using photogrammetric techniques for virtualizing historic buildings indoors requires planning more careful than laser scanning, enabling surface and texture generation in a single workflow. In addition, photogrammetry with non-metric cameras, as presented, enables any professional could afford to do these works without look to expensive equipment that would never be amortized.

Photogrammetry make possible point cloud density similar to providing by laser scanning. Futhermore, the ones generates by laser scanning not always can reproduce objects color.

Additional lighting is crucial for indoors Gothic virtualization, especially around windows and wall holes. A careful development is also important if we want to optimize work results.
The result of the methodology has been satisfactory so It could be extended to any indoor area of the church and applied to future virtualization projects. Restitution by point cloud through photogrammetric techniques combining accuracy on models and resolution quality textures.

\section{ACKNOWLEDGEMENTS}

The authors gratly thanks Liubov Rozhkova (Agisoft Sales manager) and Diana Ovod (Agisoft Tehcnical Support) for providing PhotoScan license. Thanks for fully support are given to Jorge Tomás Cueli López. In addition, we wish to thank Department of Representation and Architectonic Theory (University of La Coruña) for the usage of laser total station and laser distancemeter and Department of Technology and Graphical Representation for putting at our disposal all available resources.

\section{REFERENCES}

Ginovart, J.L., Toldrá, J.M., Costa, A., Coll, S., 2014. Close Range Photogrammetry and Constructive Characterizacion of Masonry Gothic Vaults. Journal of Construction 13(1),pp. 4755. http://www.scielo.cl/pdf/rconst/v13n1/art06.pdf (07 Nov. 2014)

Pérez, A., Cachero, R., Navarro, S., Jordá, F., López, D., Lerma, J. L., Martos, A., 2011. Close Range Photogrammetry and Terrestrial Laser Scanning: High Resolution Textured 3D Model of the Capel of The Kings in the Palencia Cathedral as a Case Study. In: XXIIIrd International CIPA Symposium. Prague, Czech Republic. Journal Geoinformatics FCE CTU. http://cipa.icomos.org/fileadmin/template/doc/PRAGUE/079.pd f (15 May 2014)

Sofocleous, E., Georgopoulos, A., Ioannides, M., Ioannidis, Ch., 2006. The geometric documentation of the Asinou Church in Cyprus. In: $7^{\text {th }}$ Symposium on Virtual Reality, Archeology and Cultural Heritage, Lefkosia, Cyprus. http://users.ntua.gr/drag/files/Download/The\%20Geometric\%20 documentation $\% 20$ of $\% 20$ the $\% 20$ Asinou $\% 20$ Church.pdf May 2014)

Tucci, G., Algostino, F., Borona, V., Chiabrando, F., 2003. 3D Modeling and restoration: From metric to thematic survey. The case study of San Francesco Al Prato in Peruga. In: XIX International CIPA Symposium. Antalya, Turkey. http://cipa.icomos.org/fileadmin/template/doc/antalya/142.pdf (15 May 2014)

Visintini, D., Siotto, E., Menean, E., 2009. 3D Modelling of the St. Anthony Abbot Church in S. Daniele del Friuli (I): From laser scanning and photogrammetry to $\mathrm{vrml} / \mathrm{x} 3 \mathrm{~d}$ model. Report on the Joint ISPRS Commission WG/V4 Workshop "3D Virtual Reconstruction and Visualization of Complex Architectures", Trento, Italy http://www.isprs.org/proceedings/XXXVIII/5W1/pdf/visintini_etal.pdf (22 May 2014). 